\title{
Interactive comment on "Water mass structure and the effect of subglacial discharge in Bowdoin Fjord, northwestern Greenland” by Yoshihiko Ohashi et al.
}

\section{Anonymous Referee \#1}

Received and published: 31 May 2019

The manuscript by Ohashi et al. examines water mass structure near a subglacial discharge plume in Bowdoin Fjord. They focus on two sample times (from 2014 and 2016) and compare and contrast the differences between the two samples. They focus on turbidity, in addition to the common/traditional temperature and salinity property analyses. They also run a model to better understand and explain the subglacial discharge and water properties that lead to the observations they have.

I am not a modeler and so I cannot address that part of the paper very well, but overall I think this is a well written paper and the topic and presentation is appropriate to this journal. I have a few major comments (conclusions about sediment visibility at the 
surface; code) and some minor comments.

You use Equation 1 and cite Chauché et al. (2014) among others. I think this citation OSD should be removed, because Chauché et al. (2014) does not use the equation that you use. Theirs is different because it contains a typo (a sign change).

Page 3 Line 35/36: Temperature and salinity do not follow the same advection diffusion equation, but you state that they do. Also, should theta here be something other than 0 , assuming the subglacial discharge water is at the same temperature as the basal ice, which is not 0 due to pressure dependence of the phase change temperature?

Page 7 Line 42: Seems like you should cite Chu (2012) here when you cite yourself. It seems odd that your 2016 paper also did not cite Chu 2012.

Page 8 line 25: Your 2016 paper used a sensor that was not high enough resolution to distinguish between subglacial discharge and surface streams that deliver sediment to the fjord surface. I disagree with your claim that subglacial and surface stream delivered sediment behave the same. Large( $r$ ) volumes of subglacial discharge are more likely to reach the surface and cause the $v$ - or $u$-shaped sediment plume often seen at the front of marine terminating glaciers. Even larger plumes may make that sediment surface pool even bigger (as you state and support with citations further down the same page). But those pools always disappear rather quickly, and I don't think that even larger subglacial discharge would impact the visual sediments at the fjord surface over large areas as you state in the paragraph beginning on line 25.

Why don't you force your model with RCM runoff estimates? Stevens et al (2016) and Mankoff et al (2016) have shown that RCM runoff estimates do approximately align with estimated runoff derived from plume \& fjord observations.

Code Availability: I commend you for releasing some of your code, but I think it is far from sufficient for me to suggest publication of this paper. I downloaded and browsed the Git repository and found it lacking. I'd like to see the following code supplied with

Interactive comment
Printer-friendly version

Discussion paper 
this paper:

1) Code archived at a permanent location such as Zenodo.

OSD

2) Zip file extract or GIT tag or something pointing to the specific code that was run, not just a living archive which in a few years may not reflect the code used in this study.

3) README files that are in English that introduce the code, the repository, how to get the specific code version used in this paper, and how to run and reproduce the simulations in this paper. When I try to compile (with pdflatex) the doc/kinaco_doc.tex file, I get a PDF but it really doesn't look correct.

3.1) Documentation of the routines. There are almost no comments in your code!

4) Not just "the model code" but an archive of the configuration and setup that you used to do the work in this paper. Where are the input files? The initial and boundary condition setup? etc. There should be data files and preprocessing scripts included.

5) Non-model code should also be provided. Please package and release your analysis scripts, the code to generate your figures, etc.

Figures: Please read Thyng et al (2016; http://dx.doi.org/10.5670/oceanog.2016.66) and consider re-doing your figures with better colorbars than what appears to be Matlab Jet.

Interactive comment on Ocean Sci. Discuss., https://doi.org/10.5194/os-2019-33, 2019.

Interactive

comment

\section{Discussion paper}

